\title{
FONOAUDIOLOGIA NAS PRÁTICAS DE HUMANIZAÇÃO: DISCURSO DO SUJEITO COLETIVO
}

\section{THE SPEECH THERAPY IN HUMANIZATION PRACTICE: DISCOURSE OF THE COLLECTIVE SUBJECT}

\author{
Marlos Suenney de Mendonça Noronha ${ }^{a^{*}}$, Vanúbia Maria Rodrigues Santos ${ }^{b^{*}}$ \\ marlos.noronha@gmail.com ${ }^{\mathrm{a}}$, vanubia25@hotmail.com ${ }^{\mathrm{b}}$ \\ Universidade Federal de Sergipe - São Cristóvão-SE, Brasil
}

\section{RESUMO:}

Introdução: A humanização compreende aspectos fundamentais no que diz respeito à convicção de que é dever dos serviços de saúde receber com dignidade a mulher, seus familiares e o recém-nascido, além de prevenir e diminuir consideravelmente $\mathrm{o}$ aparecimento de diversas patologias que podem levar à mortalidade e morbidade infantil, dentre elas as relacionadas com a Fonoaudiologia. Objetivo: analisar a adoção, pelo fonoaudiólogo, de práticas embasadas nas políticas de humanização em sua atuação em maternidades no Estado de Sergipe. Métodos: trata-se de uma pesquisa exploratória, de abordagem qualitativa que traduz a percepção da assistência, na ótica de usuárias da maternidade. Definiu-se como sujeitos da pesquisa as usuárias que utilizaram os serviços realizados na assistência ao parto e nascimento. Os dados resultantes das entrevistas foram transcritos e, posteriormente, avaliados, considerando-se a abordagem do Discurso do Sujeito Coletivo. Resultados: fizeram parte do estudo 28 participantes. Na avaliação qualitativa, as expressões-chaves (ECHs) e as ideias centrais (ICs) contemplaram aspectos referentes ao acolhimento, realização da triagem auditiva neonatal, orientações sobre amamentação e triagem auditiva neonatal, a assistência à saúde. Conclusão: espera-se que os resultados alcançados no estudo proposto possam contribuir nas reflexões sobre as boas práticas da Política Nacional de Humanização e apontar caminhos para a melhor efetividade de sua implementação, desenvolvimento e/ou continuidade de ações relacionadas à Fonoaudiologia na assistência ao parto e nascimento e os distúrbios da comunicação humana em maternidade.

Palavras-chave: Humanização da assistência; fonoaudiologia; neonatologia.

\section{ABSTRACT}

Introduction: Humanization comprises key aspects with regard to the conviction that it is the duty of health services receive with dignity the woman in labor, her family and the newborn, as well as preventing and significantly reducing the appearance of various diseases that can lead to infant mortality and morbidity, among them those related to Speech Therapy. Objective: to investigate the actions in the humanization of Speech Therapy practices in the Maternity Hospital in the State of Sergipe. Methods: it is an exploratory research with a qualitative approach that reflects the perception of the assistance, from the viewpoint of users of maternity hospitals. The investigation subjects were the users who have used the services performed in assistance to labor and birth. Data from the interviews were transcribed and subsequently evaluated, considering the Discourse of the Collective Subject Approach. Results: the study participants were 28 employees. In the qualitative evaluation, the key phrases (KPs) and the central ideas (CIs) contemplated aspects related to the host, the neonatal hearing screening, guidelines on breastfeeding and neonatal hearing screening, the health care. Conclusion: it is expected that the results achieved in the proposed study contribute reflections on the best practices of the National Policy of Humanization and point out ways for better effectiveness of its implementation, development and/or continuity of actions related to Speech Therapy in assisted childbirth and birth, and the human communication disorders in the Maternity Hospital.

Keywords: Humanization of assistance; speech, language and hearing sciences; neonatology. 


\section{Introdução}

Instituída desde 2003, a "Política Nacional de Humanização da Atenção e Gestão do SUS" veio atender a uma demanda do Sistema Único de Saúde (SUS), referente à qualidade de serviço em todos os níveis de atenção. Seu conceito consiste em estimular trocas solidárias, com resultados humanizados e aumentar o grau de resolutividade, visando modificar a assistência ao usuário nos serviços públicos de saúde, melhorando a qualidade dos atendimentos prestados pelos estabelecimentos e aperfeiçoando as relações entre profissional de saúde, gestores e usuários1.

As práticas de humanização na Atenção Primária à saúde fazem parte das discussões no Brasil e mundo. Essas discussões vêm recebendo destaque nos estudos científicos, principalmente nos periódicos de Saúde Coletiva².

Humanizar é a capacidade de oferecer um atendimento de qualidade, articulando os avanços tecnológicos com o bom relacionamento, valorizando a tecnologia da escuta, perceber o paciente como um todo, tanto pelos seus aspectos físicos como psicossociais3. Dentre os diversos espaços dos serviços de saúde, onde o debate sobre humanização tem sido mais incisivo, destacam-se as maternidades.

O Programa de Humanização no pré-natal e nascimento baseia-se nos princípios de que a humanização da Assistência Obstétrica e Neonatal é condição primeira para o adequado acompanhamento do parto e do puerpério4.

A humanização no parto gera maneiras acolhedoras, afetuosas e cordiais dos profissionais de saúde em relação à parturiente e seu recém-nascido, respeitando os tempos de seus corpos e propiciando um ambiente afável e reconfortante ${ }^{5}$.

A humanização envolve aspectos básicos no que diz respeito à certeza de que é obrigação dos estabelecimentos de saúde receber com dignidade as mulheres, seus familiares e o recém-nascido. Isto demanda caráter ético e solidário por parte dos profissionais, além de instituir um ambiente afável e estabelecer rotinas hospitalares que elimine o modelo de assistência tradicional imposto à mulher e lactente ${ }^{4}$.

As práticas humanizadoras incentivam o contato entre mãe e bebê, além de prevenir e diminuir consideravelmente o aparecimento de diversas patologias que podem levar à mortalidade e morbidade infantil, dentre elas, as de caráter fonoaudiológico, como é o caso das alterações do Sistema Sensório Motor Oral e Auditivo.

A atuação fonoaudiológica em berçários normais, berçários de risco, e em Unidade de Terapia Intensiva Neonatal (UTIN), corresponde a um importante e novo campo da Fonoaudiologia, em que a atuação está voltada para os recém-nascidos (RN) normais (RN de termo - RNT) e de risco (RN pré- termo - RNPT, baixo peso - RNBP, pequenos para a idade gestacional - RNPIG, RN portadores de patologias específicas com comprometimento do Sistema Sensório Motor Oral - SSMO e auditivo) ${ }^{6}$.

Na Fonoaudiologia, as práticas humanizadoras exigem mudanças na postura do profissional, sejam elas na realização de ações preventivas e de assistência em saúde oferecidas a gestantes/mães e lactentes, com intuito de melhor qualificar ações historicamente marcadas por ações assistencialistas e reabilitadoras pouco acolhedoras e que privilegiavam a mera aplicação de técnicas.

Para a efetivação das práticas são necessárias estratégias que possibilitem a qualificação da atenção aos pré-natais, perinatais e pós natais, buscando proferir e fomentar redes de cuidados e integração de pontos de atenção da Rede SUS de forma transversal perpassando por todas as esferas dos serviços ${ }^{4}$.

As práticas humanizadoras requerem que o fonoaudiólogo promova ações preventivas de promoção de saúde sobre o aleitamento materno, método ganguru, triagem auditiva neonatal, o desenvolvimento das funções estomatognáticas do recém-nascido, a aquisição da linguagem e do sistema imunológico.

Ao pesquisarmos sobre a humanização, atentamos que esta temática é bastante enfatizada na literatura de forma abrangente, porém a atuação e contribuição da Fonoaudiologia dentro da Política Nacional de Humanização ainda são poucos descritos. Diante do exposto, o presente estudo teve como objetivo analisar a adoção, pelo fonoaudiólogo, de práticas embasadas nas políticas de humanização em sua atuação em maternidades no Estado de Sergipe. 


\section{Método}

Trata-se de uma pesquisa exploratória, de abordagem qualitativa que traduz a percepção da assistência na ótica das puérperas.

No que tange aos preceitos éticos, após aprovação no Comitê de Ética da instituição de origem (parecer $n^{\circ} .1021788$ ), foi entregue aos participantes o Termo de Consentimento Livre e Esclarecido, no qual estavam contemplados: os objetivos da pesquisa, que a participação é voluntária, que a identidade dos entrevistados seria preservada, que o entrevistado poderia desistir de participar do estudo a qualquer momento, e que estariam totalmente isentos de qualquer custo, conforme prevê a Resolução nº 446/2012 do Conselho Nacional de Saúde ${ }^{7}$.

A pesquisa qualitativa dá significado às ações e relações humanas, não perceptíveis em estatísticas. Para o investigador, ela ordena a dinâmica social, ratificando, desconstruindo e inventando novas formas de se observar a realidade, obedecendo à lei da historicidade8. Deve ser uma aquisição de saber e adequação a novas questões, tanto no que diz respeito aos instrumentos, quanto aos grupos pesquisados.

A mesma autora diz que esta corrente metodológica não se preocupa em quantificar, mas, em compreender e explicar a dinâmica das relações sociais depositária de crenças, valores, atitudes e hábitos. Trabalha com a convivência, com a experiência, com a cotidianidade e também com a compreensão das estruturas e instituições, como resultados da ação humana objetivada. Ou seja, desse ponto de vista, "a linguagem, as práticas e as coisas são inseparáveis".

Definiu-se como sujeitos da pesquisa as puérperas que utilizaram os serviços realizados na assistência ao parto e nascimento de maternidade em Sergipe, Brasil. A amostra constituiu-se de vinte oito participantes. O critério de escolha dos participantes foi feito levando em consideração o acesso e a disponibilidade na participação do estudo, sendo que esta amostra foi demarcada ao número de entrevistas que permitiu alcançar a compreensão do fenômeno estudado.

Acredita-se que essa rotina permita pensar sobre o dia a dia das usuárias da maternidade, de for- ma a alcançar a realidade, que muitas vezes passa despercebida nas atividades diárias. É importante frisar que, por se tratar de amostra não probabilística, não se aspira à generalização dos resultados e sim a possibilidade de se alcançar compreensões acerca do fenômeno estudado, podendo este ser associado a outros espaços similares.

A estratégia da entrevista semiestruturada foi utilizada e a mesma foi realizada nas enfermarias e apartamentos da maternidade, em ambiente sem interferências, no período de Julho/2014 a Janeiro de 2015. As entrevistas foram autorizadas pela equipe gestora e, dependendo da disponibilidade e estado de saúde dos participantes, foi solicitada autorização para gravação da entrevista, que foi transcrita literalmente logo após o seu término.

A coleta de dados ocorreu seguindo o roteiro da entrevista semiestruturada, onde foram abordadas questões sobre a percepção do usuário ou do acompanhante sobre a humanização da assistência em, que se integra a Fonoaudiologia. O roteiro da entrevista semiestruturada foi constituído pelas seguintes perguntas:

a. Diga para mim como o tem sido o seu atendimento na maternidade?

b. Você foi informada que a maternidade possui um profissional de fonoaudiologia na sua equipe técnica?

c. Você recebeu esclarecimentos sobre a atuação do fonoaudiólogo e sobre a realização de procedimentos clínicos executados por esse profissional?

d. O(a) fonoaudiólogo(a) lhe atendeu com cordialidade e esclareceu todas as suas dúvidas sobre os procedimentos realizados?

Os dados resultantes das entrevistas foram avaliados, considerando-se o Discurso do Sujeito Coletivo9. Foram empregados como figuras metodológicas: a expressão-chave (E-Ch); a ideia central (IC); e o Discurso do Sujeito Coletivo (DSC).

A E-Ch desponta a peculiaridade do depoimento; é o que o sujeito pensou sobre determinado tema. A IC apresenta o sentido presente na expressão-chave. O DSC é o procedimento de tabulação e organização de dados qualitativos apresentados por meio de um discurso resumido, escrito na primeira pessoa do singular e organizado com os mais significativos extratos de depoimentos de sentido semelhante. 
O Discurso do Sujeito Coletivo baseia-se na Teoria das Representações Sociais e resume-se em analisar as ideias centrais, ancoragens e expressões-chave semelhantes, presentes nos discursos individuais. Os dados qualitativos foram transcritos e agrupados com auxílio do QualiQuantisoft, versão $1.3 \mathrm{c}$.

Para análise dos dados, as seguintes etapas foram seguidas rigorosamente ${ }^{9}$ :

1. Leitura geral das transcrições objetivando organizar uma ideia dos testemunhos apresentados nos discursos;

2. Leitura isolada de cada transcrição a partir de cada questão do roteiro investigativo.

3. Uso de instrumental da análise de discurso, representando as expressões-chave (ECHs) e identificação das ideias centrais (IC) nos discursos analisados para todas as perguntas da entrevista, objetivando revelar a sua essência.

4. Elaboração de instrumento de análise do discurso, que caracterizou separadamente cada ideia central (IC) com sua respectiva expressão-chave (ECH).

5. Construção do discurso (DSC) para cada conjunto de dados, adotando o uso de conectivos gramaticais e respeitando sua coesão, justamente para que possa sugerir uma pessoa coletiva falando como se fosse um sujeito individual de discurso.

6. Análise dos discursos de modo a atender os questionamentos da pesquisa.

As informações sociodemográficas foram analisadas, e descritas de forma percentual. Foram calculadas também medidas de incidência central para a idade.

\section{Resultados}

Fizeram parte do estudo 28 puérperas com as seguintes características: $78,57 \%$ declararam serem casados ou viver em união estável, 14,29\% solteiros, $7,14 \%$ viúvo; $18,86 \%$ possuem o ensino fundamental completo como nível máximo de escolarização, $25,00 \%$ possuem o ensino médio, $21,48 \%$ possuem o nível fundamental incompleto, $10,71 \%$ não foram alfabetizados e $3,57 \%$ possui ní- vel superior. Em relação à renda familiar, 53,57\% não souberam informar a renda e $17,46,43 \%$ possuem renda familiar de até 2 salários mínimos. A faixa etária se caracterizou, de acordo com a Organização Mundial de Saúde10: 14,29\% possuem até 18 anos, 35,71\% possuem de 19 a 24 anos e 50,00\% possuem idade acima de 25 anos.

$\mathrm{Na}$ avaliação qualitativa as expressões-chaves (ECHs) e as ideias centrais (ICs), que sugiram dos discursos com as parturientes na maternidade, contemplaram aspectos referentes ao acolhimento, triagem auditiva neonatal universal, tratamento e orientações.

A IC-1 que foi mencionada pelas puérperas consistiu nos aspectos relacionados ao Acolhimento. No Discurso do Sujeito Coletivo, os investigados relataram ter recebido assistência acolhedora tanto nos momentos que antecederam o nascimento de seus filhos, quanto ao longo de toda a internação, consoante ilustra o DSC1.

Os profissionais foram simpáticos e me acolheram bem. Logo quando cheguei à maternidade, eles me atenderam e fui encaminhada para sala de espera. Durante todo o período vinham saber se estava precisando de alguma ajuda. Às vezes, elas demoravam porque estavam apoiando outras grávidas. Os profissionais eram pacientes no trabalho e sempre me orientavam nas minhas dúvidas. (DSC1 - Discurso do Sujeito Coletivo das parturientes e familiares sobre o acolhimento na maternidade).

Aspectos relacionados à realização da triagem auditiva neonatal universal foram mencionados pelas puérperas na IC-2. No Discurso do Sujeito Coletivo, as parturientes afirmaram não terem conhecimento sobre a Triagem Auditiva Neonatal Universal e seus objetivos, segundo descreve o DSC2.

Não sei o que é o teste da orelhinha. Eu nunca fui informada sobre ele e não sei que realiza o exame. O que me falaram é que meu bebê precisa realizar o exame ainda na maternidade. Eu acredito que seja para saber se ele tem algum problema no ouvido, verificar se ele é surdo. Acredito que a doutora deve 
colocar um aparelho no ouvido que tira um pouco de sangue. Deve ser como o teste do pezinho. (DSC2 - Discurso do Sujeito Coletivo das parturientes e familiares sobre a realização da triagem auditiva neonatal universal).

A IC-3 que foi referida pelas puérperas consistiu nos aspectos sobre as orientações à saúde da criança. Percebeu-se no Discurso do Sujeito Coletivo a carência de orientações sobre a amamentação e triagem auditiva neonatal universal, de acordo com o DSC3.

Quem esclareceu as minhas dúvidas? A enfermeira e assistente social daqui. Uma profissional muito simpática e educada. Não tive a oportunidade de perguntar o nome, mas ela me deu várias informações e orientações sobre o teste da orelhinha e amamentação. Ela parece que é pediatra ou do banco de leite. No final, ela me deu um cartão e um informativo para ler depois. (DSC3 - Discurso do Sujeito Coletivo das parturientes e familiares sobre as orientações sobre a amamentação $e$ triagem auditiva neonatal).

A IC-4 que foi relatada pelas puérperas consistiu nos aspectos relacionados à assistência no parto e nascimento recebida na maternidade. No Discurso do Sujeito Coletivo, as puérperas deste estudo relataram satisfação com a assistência no parto e nascimento recebida na maternidade. Valorizaram a importância de um relacionamento afetivo com a equipe. Sabe-se que a educação e o respeito são práticas efetivadas na maternidade e preconizadas pela Política Nacional de Humanização, conforme relata o DSC4.

$O$ atendimento na maternidade está sendo ótimo. Toda hora aparece um profissional me perguntando se está tudo bem comigo e com o bebê. Eles se preocupam com a nossa saúde e sempre nos tratam bem, apesar de nossa falta de paciência por causa das dores ocasionadas pelo parto. Tudo é bom e não tenho o que reclamar dos atendimentos e organização. Toda hora meus familiares têm notícias sobre nossa saúde. (DSC4 - Discurso do
Sujeito Coletivo das parturientes e familiares sobre à assistência no parto e nascimento).

\section{Discussão}

O termo acolhimento tem sido utilizado com frequência nos serviços de saúde. O acolhimento na saúde retrata temas relacionados à organização e prática do trabalho, destacando aspecto ético e político no comportamento dos profissionais no relacionamento com os usuários do serviço, como também na reavaliação do modelo assistencial e de gestão, objetivando ampliação do acesso a rede, propiciando uma assistência interdisciplinar sem negar outras abordagens que compreendam as necessidades da população ${ }^{11}$.

Um dos princípios que interpõe as práticas de humanização na assistência ao parto e nascimento é a integralidade que deve considerar as ações assistenciais objetivando as relações de acolhimento, dignidade, vínculo e respeito entre os profissionais, beneficiários do serviço e as instituições ${ }^{12}$.

Quando se trata da assistência ao parto e nascimento, $o$ ato de acolher torna-se um trajeto para os profissionais de saúde que ambicionam o resgate da assistência humanística nos serviços de saúde ${ }^{13}$.

As práticas de humanísticas na assistência ao parto e nascimento envolvem um conjunto de conhecimentos, práticas e atitudes que visam à promoção do parto, do nascimento saudável e à prevenção da morbimortalidade materna e perinatal; devendo ser iniciada no pré-natal, garantindo que a equipe de saúde realize procedimentos benéficos para a mulher e o bebê e preserve a privacidade e a autonomia da mulher ${ }^{14}$.

O fonoaudiólogo não deve ser exceção quando tratamos as práticas abordadas na Política Nacional de Humanização, na assistência ao parto e nascimento. Ele deve atuar na prevenção junto a pais e cuidadores, e na detecção de possíveis alterações nas funções do sistema sensório motor oral, também considerando o desenvolvimento neuropsicomotor da criança $\mathrm{a}^{15}$.

A sua participação em equipes interdisciplinares é de extrema importância, por deter conhecimentos de anatomia e fisiologia das funções 
envolvidas no sistema sensório motor oral e auditivas, sendo o profissional capacitado no diagnóstico e tratamento das suas alterações, que envolve estimulação da alimentação oral, promoção do aleitamento materno, e aos aspectos relacionados à audição $0^{6},{ }^{15}$.

Especificamente, na maternidade, o fonoaudiólogo atua com pacientes e familiares de recém-nascidos prematuros, ressaltando que estes têm um alto risco para dificuldades alimentares devido a sua imaturidade neurológica, alterações no tônus muscular e reflexos orais. Tais alterações podem interferir no desenvolvimento da sucção, deglutição, respiração $0^{6},{ }^{15}$.

Além disso, compete ao fonoaudiólogo à promoção e estimulação da alimentação oral, o auxílio na transição do uso da sonda enterais para seio materno, objetivando melhorias da qualidade de vida desses recém-nascidos e orientações aos pais e cuidadores. Para o serviço, a realização destas ações pode favorecer a diminuição do tempo de internação e infecções hospitalares ${ }^{6,15}$.

É importante lembrar que a prática do acolhimento nasceu de uma conjuntura de escassez dos serviços de saúde para contestar a qualidade das necessidades e pleitos dos usuários. Logo, o acolhimento é recomendado como uma tática para programar exemplos de assistência humanizada com audácia e qualidade. Para que os serviços sejam conclusivos é indispensável aceitar o beneficiário como membro da ação assistencial ${ }^{16}$.

Sabe-se que existe uma dependência das práticas de humanização com o processo do acolhimento que está relacionada com o desempenho adequado dos profissionais e da sua receptividade perante os envolvidos nesse processo, equipando-lhes de ajuda, do respeito e do contentamento na assistência ${ }^{16}$.

É notório que as práticas acolhedoras nos serviços de saúde têm favorecido o aperfeiçoamento da relação entre profissionais de saúde e usuários, favorecendo uma maior intimidade entre esses dois sujeitos ${ }^{17}$. Elas envolvem conhecimentos, práticas e atitudes que objetivam o acesso ao parto, possibilitando o nascimento saudável e a precaução da morbimortalidade materna e perinatal ${ }^{18}$.

Faz-se necessário ressaltar que construção de vínculos não deve ser esquecida no processo de acolhi- mento. Ela deve ser realizada a partir de movimentos tanto dos usuários quanto da equipe. Por parte do usuário, a criação de vínculo será favorecida quando ele acreditar que a equipe poderá contribuir de algum modo para a sua saúde e sentir que esta equipe se corresponsabiliza por esses cuidados ${ }^{19}$.

Ao tratar sobre os aspectos relacionados à realização da triagem auditiva neonatal universal, é importante enfatizar que a Política Nacional de Humanização preconiza a proteção e o desenvolvimento da autonomia e da equidade entre os indivíduos e coletividade, bem como a garantia da universalidade do acesso, mediante ampla cobertura no atendimento aos portadores de deficiência auditiva no Brasil, garantindo a integralidade e o controle social na saúde auditiva. Compete às três esferas de governo, a regulação, o controle e a avaliação das ações de atenção à saúde da pessoa portadora de deficiência auditiva ${ }^{19}$.

No local onde o estudo foi realizado, os recém-nascidos permanecem no alojamento conjunto com as respectivas genitoras. Antes de receber alta médica, o setor responsável pelo agendamento de exames informa às genitoras o dia e horário em que os recém-nascidos podem realizar a Triagem Auditiva Neonatal Universal - TANU.

A Triagem Auditiva Neonatal Universal (TANU), mais conhecida como "Teste da Orelhinha”, garantida pela Lei Federal no 12.303/2010, é uma avaliação que busca detectar a perda auditiva congênita e/ou adquirida no período neonatal o mais precocemente possível ${ }^{19}$.

O procedimento deve ser realizado em todos os recém-nascidos, preferencialmente até o final do primeiro mês, o que possibilitará um diagnóstico mais definitivo por volta do quarto e quinto meses, bem como o início da reabilitação até os seis meses de idade. Nessa fase, a criança encontra-se ainda no período crítico de maturação e plasticidade funcional do sistema nervoso central, permitindo um prognóstico favorável em relação a seu desenvolvimento global ${ }^{20}$.

A Triagem Auditiva Neonatal Universal é realizada no berçário em sono natural, com duração de cinco a dez minutos e não existe contraindicação. No procedimento, a criança avaliada não sente incômodo, não exige nenhum tipo de intervenção invasiva e é absolutamente inócuo ${ }^{21}$. 
A avaliação da acuidade auditiva pode englobar análises comportamentais, eletroacústicas e/ ou eletrofisiológicas para a identificação da deficiência auditiva ${ }^{22}$.

O diagnóstico precoce de problemas auditivos possibilita uma adaptação precoce de aparelhos de amplificação sonora e a reabilitação auditiva, por consequência, melhores resultados no desenvolvimento auditivo e de linguagem destas crianças ${ }^{23,24,25}$.

A terapia fonoaudiológica nos primeiros meses de vida amplia a possibilidade de se desfrutar ao máximo as habilidades linguísticas, no exercício acadêmico e na melhoria social e emocional das crianças $^{26,27}$.

Diante dos relatos percebe-se a necessidade de institucionalizar na maternidade oficinas temáticas sobre o desenvolvimento linguístico e auditivo humano, a importância da realização da Triagem Auditiva Neonatal Universal e a sua finalidade na maternidade para as usuárias do serviço.

É importante frisar hoje, no Brasil, existem condições e tendências para um diagnóstico auditivo precoce. Entretanto, persiste a necessidade melhorias nas relações e trocas de saberes os pediatras, neonatologistas, otorrinolaringologistas e fonoaudiólogos, objetivando um aperfeiçoamento propiciando um melhor prognóstico para essas crianças ${ }^{27}$

Quanto as orientações à saúde da criança, é importante enfatizar que o fonoaudiólogo que atua em ambientes neonatais tem conquistado seu espaço na equipe multidisciplinar apesar da sua recente inserção nesta área28,29. Nela, o profissional pode trabalhar em berçários normais, berçários de risco, e em Unidades de Terapia Intensiva Neonatal no atendimento de recém-nascidos normais e/ou de risco ${ }^{30}$.

O papel do fonoaudiólogo junto à equipe multidisciplinar está na orientação quanto às posturas adequadas para alimentação e estimulação dos casos patológicos, além de esclarecimentos gerais sobre dúvidas ligadas às funções de sucção, deglutição, respiração e audição ${ }^{20,21}$. Neste caso, a meta é um trabalho cooperativo com contínua troca de informações, sempre na busca da promoção à saúde.

É importante que o fonoaudiólogo participe de oficinas para gestantes com objetivo de proporcio- nar orientações sobre os cuidados no banho; o uso de objetos no ouvido; orientações na amamentação e outros. As atividades devem ser dirigidas as gestantes e profissionais de saúde desde o pré-natal $^{31}$.

O trabalho deve ser iniciado com explicações dadas sobre o processo etiológico das estruturas relacionadas ao funcionamento da amamentação e audição, alertando sobre a importância da detecção precoce de alterações no sistema sensório motor oral, linguagem e na audição, como também oferecendo orientações sobre cuidados básicos que a mãe poderá ter com seu filho, prevenindo alterações e respectivos exames para diagnóstico ${ }^{20,21}$.

Apesar das conquistas no que refere à inserção do fonoaudiólogo em ambientes neonatais, verifica-se que a avaliação dos serviços de saúde auditiva está focalizada na infraestrutura e na produção dos procedimentos. Há uma necessidade de sistematizar a avaliação das habilidades linguísticas e auditivas nos serviços para contribuir no plano terapêutico dos usuários32,33. É preciso por em prática o conceito da clínica ampliada e o fonoaudiólogo deve se apropriar de seus saberes e técnicas e evitar que outros profissionais sejam visualizados como detentores de tal saber.

Uma das premissas da Política Nacional de $\mathrm{Hu}-$ manização é o usuário ter esclarecidas as suas dúvidas. Nos discursos foi evidenciado que a maioria das parturientes e acompanhantes foi acolhida em momentos de dúvidas, pelos profissionais da Pediatria, Serviço Social e Enfermagem. Tais profissionais deram assistência nos momentos de ocorrências no leito.

Com referência ao fonoaudiólogo, existe uma ausência de comunicação sobre as suas práticas profissionais que correspondem à efetivação de estratégias como orientações e informação referentes à Triagem Auditiva Neonatal Universal.

Sobre a assistência à saúde, a humanização da assistência no parto e nascimento evidencia a importância das parturientes conversarem com os profissionais da saúde e tirarem suas dúvidas, ao falar com o profissional para que este lhe passe tranquilidade. A genitora deve se sentir cuidada e tratada com respeito para poder confiar, sentindose segura ${ }^{34}$.

A assistência obstétrica no Brasil é evidenciada pelo exagero de interferência 
no parto, o que tem colaborado para a ampliação de taxas de cirurgias cesarianas e a morbimortalidade materna e perinatal ${ }^{35}$.

$\mathrm{O}$ entendimento do fenômeno dos altos índices de cesarianas no Brasil leva em consideração a multiplicidade e complexidade de fatores culturais envolvidos (medicalização, crença histórica e errônea de que tem impacto na diminuição da mortalidade perinatal, medo do parto normal, experiências negativas com partos anteriores) e assistência médica ${ }^{35,36,37,38,39}$.

O fonoaudiólogo na assistência ao parto e nascimento deve atuar na orientação quanto o ato de amamentar, sobre a dificuldade na pega, a dor e o trauma mamilar, o posicionamento incorreto do bebê no peito, na ausência do leite, na insegurança para amamentar e ingurgitamento mamário. Além disso, ele precisa esclarecer sobre os riscos ocasionados pelo desmame precoce, sucção débil e uso precoce de chupetas e mamadeiras ${ }^{28}$. Da mesma forma, há uma necessidade que os familiares sejam orientados sobre aspectos relacionados ao desenvolvimento linguístico e auditivo na infância.

É importante salientar que a assistência a ser entendida como um modo de cuidado centrado na voz do indivíduo, no respeito à sua autonomia. Portanto, o uso de tecnologias leves que perpassam pela escuta, apreensão e satisfação de necessidades devem ser utilizadas constantemente. O enfoque desta assistência tem como alvo as relações de cuidado a parturientes e neonatos, mas, deve adequar-se para os cuidados ao profissional, sujeitos e atores dinâmicos do processo de produção de saúde.

\section{Conclusões}

Esta pesquisa aponta para a necessidade de aprimorar a Política Nacional de Humanização na assistência ao parto e nascimento para a atuação do fonoaudiólogo no serviço investigado, que pode ser estendida de alerta para outros espaços onde este profissional atua, já que é evidente a escassez de publicações que correlacione à assistência fonoaudiológica e práticas humanizadas.

Revendo o objetivo proposto, pode-se observar que os participantes do estudo receberam orientações sobre temáticas que, contemplam a Fonoaudiologia. Entretanto, muitas informações sobre o aleitamento materno, desenvolvimento auditivo e exames complementares para diagnóstico foram apresentados de forma genérica pela equipe da instituição.

Verifica-se por meio do Discurso do Sujeito Coletivo que os profissionais da Saúde, em especial do Serviço Social e Banco de Leite, criam estratégias para atender às necessidades dos usuários desenvolvendo ações como palestras, entregas de panfletos, campanhas de estímulos ao aleitamento materno e doação do leite materno, orientações às parturientes e seus familiares sobre o pré e pós-natal.

Tais atividades são extremamente representativas e possuem grande relevância na PNH. Entretanto, há uma necessidade de incluir outras categorias profissionais com atuação na assistência ao parto e nascimento nas referidas ações, em especial o fonoaudiólogo.

É preocupante a fragilidade na informação da realização da Triagem Auditiva Neonatal Universal - TANU porque pode levar a não aderência da família para sua realização. O fonoaudiólogo que atua em Neonatologia deve apropriar-se da orientação sobre o desenvolvimento auditivo infantil e seu diagnóstico precoce sobre possíveis alterações auditivas. Vale lembrar que foi árdua a luta para tornar-se efetivo este procedimento em todas as maternidades do país.

\section{Referências}

1. Brasil. Ministério da Saúde. Secretaria de Atenção à Saúde. Programa Nacional de Humanização da Assistência Hospitalar. Brasília (DF): Ministério da Saúde, 2001. Disponível em: http://bvsms.saude.gov.br/bvs/publicacoes/ pnhah01.pdf. Acesso em 17/08/2016.

2. Goulart BNG, Chiari BM. Humanização das práticas do profissional de saúde: contribuições para reflexão. Ciênc. saúde coletiva [periódico na Internet]. 2010 Jan [acesso em 17/09/2016]; 15(1):255-268. Disponível em: http://www.scielo.br/scielo.php?script=sci_arttext\&pi$\mathrm{d}=$ S1413-81232010000100031\&lng=en.

3. Maynart WHC, Albuquerque MCS, Brêda MZ, Jorge JS. A escuta qualificada e o acolhimento na atenção psicossocial. Acta paul. enferm. [periódico da Internet]. 2014 Ago [acesso em 17/09/2016]; 27(4): 300-304. Disponível em: http://www.scielo.br/scielo.php?script=sci_arttext\&pid=S0103-21002014000400003\&lng=en. 
4. Programa de Humanização no Pré-natal e Nascimento. Rev. Bras. Saude Mater. Infant. [periódico da Internet]. 2002 Abr [acesso em 17/09/2016]; 2(1): 69-71. Disponível em http://www.scielo.br/scielo.php?script=sci_arttex$\mathrm{t} \&$ pid $=$ S1519-38292002000100011\&lng=en.

5. Farias AS. Assistência ao parto humanizado: Sensibilização da equipe de enfermagem [Monografia]. Fortaleza (CE): Escola de Saúde Publica do Ceará; 2010.

6. Girardi ALFN. Intervenção precoce e a clínica fonoaudiológica. Estilos clin. [periódico da Internet]. 2010 jan [acesso em 17/09/2016]; 15(1): 144-163. Disponível em: http://pepsic. bvsalud.org/scielo.php?script =sci_arttext\&pi$\mathrm{d}=\mathrm{S} 1415-71282010000100010 \& \operatorname{lng}=\mathrm{pt} \& \mathrm{nrm}=\mathrm{iso}$.

7. Brasil. Ministério da Saúde. Conselho Nacional de Saúde. Resolução n. 466, de 12 de dezembro de 2012. Aprova diretrizes e normas regulamentadoras de pesquisas envolvendo seres humanos. Brasília, Diário Oficial da União, 12 dez. 2012.

8. Minayo MCS. O desafio do conhecimento: Pesquisa qualitativa em saúde. 9a edição revista e aprimorada. São Paulo (SP): Hucitec; 2006. 406 p.

9. Lefevre F, Lefevre AMC. O discurso do sujeito coletivo: um novo enfoque em pesquisa qualitativa. Caxias do Sul (RS): Educs, 2003.

10. World Health Organization. Young people's health a challenge for society. Geneva: World Health Organization; 1986. (WHO Technical Report Series, 731).

11. Tesser CD, Poli Neto P, Campos GWS. Acolhimento e (des)medicalização social: um desafio para as equipes de saúde da família. Ciênc Saúde Coletiva. 2010;15(Suppl.3):3615-24.

12. Duarte Elysângela Dittz, Sena Roseni Rosângela de, Xavier César Coelho. Processo de trabalho na Unidade de Terapia Intensiva Neonatal: construção de uma atenção orientada pela integralidade. Rev. esc. enferm. USP [periódico da Internet]. 2009 Set [acesso em 17/09/2016]; 43(3): 647-654. Disponível em: http://www.scielo.br/scielo.php?script=sci_arttext\&pi$\mathrm{d}=$ S0080-62342009000300021\&lng=en .

13. Maestri E, Nascimento ERP, Bertoncello KCG, Martins JJ. Estratégias para o acolhimento dos familiares dos pacientes na unidade de terapia intensiva. Rev. enferm. UERJ. 2012;20(1):73-8.

14. Oliveira NES, Oliveira LMAC, Lucchese R, Alvarenga GC, Brasil VV. Humanização na teoria e na prática: a construção do agir de uma equipe de enfermeiros. Rev Eletr Enf [periódico da internet]. $2013 \mathrm{abr} /$ jun [Acesso em 17/08/2016]; 15(2): 334-343. Disponível em: http:// www.fen.ufg.br/fen_revista/v15/n2/pdf/v15n2a04.pdf

15. Pinheiro JVL, Oliveira NM, Júnior HVM. Procedimentos fonoaudiológicos em recém-nascido de alto risco. Rev. Bras. Prom. Saúde. 2010; 23(2):175-80.
16. Hoga LAK. A dimensão subjetiva do profissional na humanização da assistência à saúde: uma reflexão. Rev. esc. enferm. USP [periódico da Internet]. 2004 Mar [acesso em 17/09/2016]; 38(1): 13-20. Disponível em: http://www.scielo.br/scielo.php?script=sci_arttext\&pi$\mathrm{d}=$ S0080-62342004000100002\&lng=en

17. Lopes GVDO, Menezes TMO, Miranda AC, Araújo KL, Guimarães ELP. Acolhimento: quando o usuário bate à porta. Rev. bras. enferm. [periódico da Internet]. 2014 Fev [acesso em 28/09/2016]; 67(1): 104-110. Disponível em: http://www.scielo.br/scielo.php?script=sci_arttext\&pid=S0034-71672014000100104\&lng=pt

18. Brasil. Ministério da Saúde. Parto, aborto e puerpério: assistência humanizada a mulher. Brasília (DF): 2001.

19. Brasil. Presidência da República. Lei no . 12.303/2010 (Lei Ordinária) 02/08/2010 [Acessado em 15/08/2016]. Disponível em: http://www.planalto.gov.br/ccivil_03/_ Ato2007-2010/2010/Lei/L12303.htm.

20. Hilú MRPB, Zeigelboim BS. O conhecimento, a valorização da triagem auditiva neonatal e a intervenção precoce da perda auditiva. Rev. CEFAC [periódico da Internet]. 2007 Dez [acesso em 18/08/2016]; 9(4): 563-570. Disponível em: http://www.scielo.br/scielo.php?script=sci_arttext\&pid=S1516-18462007000400017\&lng=en.

21. Garcez LW. Possibilidades e limites da atuação fonoaudiológica em berçários [Monografia]. Porto Alegre (RS): Centro de Especialização em Fonoaudiologia Clínica; 1999.

22. Kemp AAT, Delecrode CR, Silva GC, Martins F, Frizzo ACF, Cardoso ACV. Triagem auditiva neonatal em uma maternidade de baixo risco do interior paulista. Braz. j. otorhinolaryngol. [periódico da Internet]. 2015 Out [acesso em 20/09/2016]; 81(5): 505-513. Disponível em: http://www.scielo.br/scielo.php?script=sci_arttext\&pi$\mathrm{d}=$ S1808-86942015000500505\&lng=pt.

23. Campos ACM, Shirane HY, Takemoto PVA, Lourenço EA. Triagem auditiva neonatal universal: conhecimento dos pediatras e neonatologistas em Jundiaí, São Paulo, Brasil . Braz. j. otorhinolaryngol. [periódico da Internet]. 2014 Out [acesso em 28/09/2016]; 80(5): 379-385. Disponível em: http:// www.scielo.br/scielo.php?script $=$ sci_arttext $\&$ pi$\mathrm{d}=$ S1808-86942014000500379\&lng=en.

24. Lewis DR, Marone SAM, Mendes BCA, Cruz OLM, Nóbrega M. Comitê multiprofissional em saúde auditiva: COMUSA. Braz. j. otorhinolaryngol. (Impr.) [periódico de Internet]. $2010 \mathrm{Fev}$ [acesso em 29/09/2016]; 76(1): 121-128. Disponível em: http:// www.scielo.br/scielo.php?script $=$ sci_arttext $\&$ pi$\mathrm{d}=$ S1808-86942010000100020\&lng=en.

25. Yoshinaga-Itano C, Sedey A. Language, speech and social-emotional development of children who are deaf or hard of hearing: the early years. Volta Rev. 2000;100(5):213-34. 
26. Tschiedel RS, Bandini HHM, Bevilacqua MC. Diagnóstico da deficiência auditiva na infância: uma avaliação do nível de conhecimento dos pediatras de uma cidade da região Centro-Oeste paulista. Pediatr Mod. 2000;36(9):607:610:614:617:passim-607-612-615-618.

27. Rogério AFH, Almeida EOC, Hidaka MTU, Amado BCT. Triagem auditiva neonatal: caracterização da demanda/ território e exames auditivos. Rev. CEFAC [periódico de internet]. 2014 Aug [acesso 02/04/2017]; 16(4): 1060-1068. Disponível em: http://www.scielo.br/scielo.php?script=sci_arttext\&pi$\mathrm{d}=\mathrm{S} 1516-18462014000401060 \& \ln \mathrm{g}=\mathrm{en}$.

28. Soares JPO, Novaes LFG, Araújo CT, Vieira ACC. Amamentação natural de recém-nascidos pré-termo sob a ótica materna: uma revisão integrativa. Rev. CEFAC [periódico de internet]. 2016 Fev [acesso em 02/04/2017]; 18(1): 232-241. Disponível em: http://www.scielo.br/scielo.php?script=sci_arttext\&pi$\mathrm{d}=$ S1516-18462016000100232\&lng=en.

29. Calado DFB, Souza R. Intervenção fonoaudiológica em recém-nascido pré-termo: estimulação oromotora e sucção não-nutritiva. Rev. CEFAC [periódico da Internet]. 2012 Fev [acesso 29/09/2016]; 14(1): 176-181. Disponível em: http://www.scielo.br/scielo.php?script=sci_arttext\&pid=S1516-18462012000100021\&lng=en .

30. Tenório RMSA. Avaliação do Grau de Implantação do Dispositivo Acolhimento nas Unidades de Saúde da Família da Cidade do Recife. [Dissertação] Recife (PE): Instituto de Medicina Integral Professor Fernando Figueira; 2011.

31. Maia RM, Silva MAM, Tavares PMB. Saúde auditiva dos recém-nascidos: atuação da fonoaudiologia na Estratégia Saúde da Família. Rev. CEFAC [periódico da Internet]. 2012 Abr [acesso em 29/09/2016]; 14(2): 206-214. Disponível em: http://www.scielo.br/scielo.php?script=sci_arttext\&pid=S1516-18462012000200003\&lng=en .

32. Penna LM, Lemos SMA, Alves CRL. Habilidades linguísticas e auditivas de crianças usuárias de aparelho auditivo. Braz. j. otorhinolaryngol. [periódico da Internet]. 2015 Abr [acesso em 29/09/2016]; 81(2): 148-157. Disponível em: http://www.scielo.br/scielo.php?script=sci_arttext\&pid=S1808-86942015000200148\&lng=en.

33. Campos Ana Carolina Moreno de, Shirane Henrique Yassuhiro, Takemoto Paulo Vitor Atsushi, Lourenço Edmir Américo. Triagem auditiva neonatal universal: conhecimento dos pediatras e neonatologistas em Jundiaí, São Paulo, Brasil . Braz. j. otorhinolaryngol. [periódico da Internet]. 2014 Out [acesso em 29/09/2016]; 80(5): 379-385. Disponível em: http://www.scielo.br/scielo.php?script=sci_arttext\&pid=S1808-86942014000500379\&lng=en .
34. Brasil. Ministério da Saúde . Humaniza SUS: acolhimento com avaliação e classificação de risco. Brasília (DF): Ministério da Saúde, 2004. 44 p. Disponível em: http:// bvsms.saude.gov.br/bvs/publicacoes/acolhimento.pdf.

35. Caparroz SC. O resgate do parto normal: contribuições de uma tecnologia apropriada. Joinville: Univille. 2003.

36. Barros AJD, Santos IS, Matijasevich A, Domingues MR, Silveira M, Barros FC et al . Patterns of deliveries in a Brazilian birth cohort: almost universal cesarean sections for the better-off. Rev. Saúde Pública [periódico da Internet]. 2011 Ago [acesso em 29/09/2016]; 45(4): 635-643. Disponível em: http://www.scielo.br/scielo.php?script=sci_arttext\&pid=S0034-89102011000400001\&lng=en .

37. Rattner D. Sobre a hipótese de estabilização das taxas de cesárea do Estado de São Paulo, Brasil. Rev. Saúde Pública [periódico da Internet]. 1996 Fev [acesso 29/09/2016]; 30(1): 19-33. Disponível em: http:// www.scielo.br/scielo.php?script=sci_arttext \&pi$\mathrm{d}=$ S0034-89101996000100004\&lng=en.

38. Faúndes A, Pádua KS, Osis MJD, Cecatti JG, Sousa $\mathrm{MH}$. Opinião de mulheres e médicos brasileiros sobre a preferência pela via de parto. Rev. Saúde Pública [periódico da Internet]. 2004 Ago [acesso em 29/09/2016]; 38(4): 488-494. Disponível em: http:// www.scielo.br/scielo.php?script $=$ sci_arttext \&pi$\mathrm{d}=$ S0034-89102004000400002\&lng=en.

39. Mandarino NR, Chein MBC, Monteiro Júnior FC, Brito LMO, Lamy ZC, Nina VJS et al. Aspectos relacionados à escolha do tipo de parto: um estudo comparativo entre uma maternidade pública e outra privada, em São Luís, Maranhão, Brasil. Cad. Saúde Pública [periódico da Internet]. 2009 Jul [acesso em 29/09/2016]; 25(7): 1587-1596. Disponível em: http://www.scielo.br/scielo.php?script=sci_arttext\&pid=S0102-311X2009000700017\&lng=en.

Como citar este artigo:

Souza DR, Toigo AM. O efeito do treinamento de alta intensidade nos níveis glicêmicos empessoas com diabetes mellitus tipo 2. Rev. Aten. Saúde. 2018;16(57):45-54. 